Mr. McLennan has done his arithmetic correctly, but the calculation is really extremely simple, as thus :-

The moon's mass is I/8oth that of the earth, which is $6 \times 10^{21}$ tons. At the moon's distance, which is 60 earth's radii, terrestrial gravity is reduced to $1 / 3600$ th of its value at the earth's surface. Consequently, the weight of the moon. i.e. the earth's gravitative pull on it, is equal to the ordinary commercial weight of

$$
1 / 3600 \times 1 / 80 \times 6 \times 10^{21} \text { tons. }
$$

An alternative, but not a supplementary, way of doing the sum is to say that the moon revolves through the angle $2 \pi$ in, say, $27 \frac{2}{3}$ days, and that therefore the centripetal force necessary to hold it in is

$$
m \omega^{2} r=\frac{6 \times 10^{21}}{80} \text { tons } \times\left(\frac{2 \pi}{27 \frac{1}{3} \text { days }}\right)^{2} \times 60 \times 4000 \text { miles. }
$$

The acceleration part of this is about 13,000 miles per day per day, which is the same as $32 / 3600$ feet per second per second; and this is obviously in accordance with the law of inverse square. Oliver Lodge.

\section{A Direct Estimate of the Minimum Age of Thorianite.}

I WISH to record an experiment lately made which affords more direct proof of the great antiquity of radioactive minerals than anything previously attempted.

The principle of the method is to determine (I) the total accumulated helium in the material; (2) the rate of formation in the same material at present.

A sample of thorianite was found to contain 9 c.c. helium per gram.

Four hundred grams of this thorianite was got into solution, and all traces of helium boiled out with scrupulous care. After it had been allowed to stand for seven weeks, the solution was boiled out again. A little nitrogen and nitric oxide were evolved. These were removed by charcoal cooled in liquid air, and the residual helium collected in the capillary of a McLeod gauge. $\mathrm{D}_{3}$ could be seen in the spectrum, but the volume of the gas was too small to measure. It was certainly less than $2 \times$ Io $^{-6}$ c.c., perhaps much less.

Thus the annual rate of production of helium per gram is less than $3.7 \times 10^{-8}$ c.c. The 9 c.c. initially present cannot, therefore, have accumulated in a less time than 240 million years. Experiments on a larger scale, which are in progress, will probably lead to an extension of this estimate.

Prof. Joly, in his interesting book, " Radio-activity and Geology," has brought various objections against the radio-active method of measuring geological age. These will require to be carefully weighed. I may remark, however, that in the present case no uncertainty arises on the ground that the substance may formerly have contained much more uranium or thorium than at present, for thorianite consists almost entirely of the oxides of thes elements.

Imperial College of Science, May $\mathbf{r}$.

\section{Sense of Smell in Flies.}

By far the most efficient of fly-destroyers with which I am acquainted is a dilute solution of formaldehyde. If two teaspoonfuls of formalin (40 per cent. formaldehyde) be added to a soup-plate filled with water, flies go to it, one after the other, to drink, especially in the early afternoon. Some die in the water; many fall in the immediate neighbourhood of the plate; others succumb on windowsill or floor. As the result of leaving a single plateful of the solution on the kitchen table (I am writing in the south of France) hundreds of dead flies are each day swept up from the floor. Formalin water is free from the gruesome associations of fly-papers and other traps which hold their struggling victims. It may even be turned to ornamental uses. A wire cage placed in the centre of the dish may be crowned with flowers, which flourish equally as well, with some slight but interesting changes in tint, in dilute formalin as in pure water. The solution neither attracts nor repels flies. Two similar dishes placed side by side, the one containing pure water and the other formalin, are visited, so far as one can judge, with equal frequency. It is somewhat strange that so No. 2063 , vol. 80$]$ small a dose proves fatal when taken into the fly's alimentary canal. I find that, to free a room from flies by vaporising formalin, the air must be rendered quite irrespirable by a human being. The room needs to be amply ventilated before one ventures into it.

The interest which attaches to this observation, that flies will drink a solution of formadehyde, lies in the proof which it affords that the mechanism of their sense of smell is similar to our own. No volatile body the density of which is not greater than that of air is a stimulant of our olfactory membrane. Formaldehyde, $\mathrm{H}, \mathrm{COH}$, has a density of ${ }^{15}$ only. Playing in paradoxes, one might say that it undoubtedly has a malignant odour, but we cannot smell it. If the nose be placed close to a vessel containing a dilute solution of formalin a scent is recognisable, but this I take to be due (a chemist will correct me) to impurities present in the commercial product. Yet I find that when I sit within a yard of it my eyes begin to smart. In this respect, however, I am, I know, exceptionally sensitive. I cannot dissect specimens preserved in formalin until after they have been long soaked in water and spirit frequently changed. Once, when conducting a viva voce examination with the aid of formalin preparations, I developed so acute and painful, although happily transient, an attack of conjunctivitis as made it impossible for me to attend the examinees' meeting. The fact that so deleterious a volatile body as formadehyde does not appeal to our sense of smell would seem to confirm the only theory of the physics of olfaction at present plausible, though far from comprehensible, namely, that which attributes to the hairs of the cells of the olfactory membrane the capacity of responding to the alterations in the vibration frequency or amplitude of molecules of air which are caused by the presence amongst them of heavier molecules.

Mentone.

\section{The Production of Radium from Uranium.}

EXPERIMENTS on which I have been engaged for the past six years have until now failed to establish the production of radium from uranium. With carefully purified uranium salts, using considerable quantities, the growth is too small to be detected for the first two or three years, and is less than $1 /$ ro, oooth of what would occur if a direct change of uranium into radium took place. With commercial uranyl nitrate, on the other hand. purified from radium by precipitating barium sulphate in the solution, a distinct though small production of radium was observed in 1905, and subsequently confirmed (Phil. Mag., October, 1908, 632). This is explained by the existence of an intermediate parent of radium in the series with a very long period of life, which has been found by Boltwood and by Rutherford in preparations of actinium, and recently isolated by the former from uranium minerals, and called " ionium."

I have now been able to establish the production of radium in all the solutions of very carefully purified uranyl nitrate prepared by Mr. T. D. Mackenzie and myself (Phil. Mag., August, 1907, 272). Three separate solutions containing 255,408 , and 278 grams of uranium (element), and of age since purification at the present time respectively $3.53,2.40$, and 2.73 years, have been kept under observa. tion. The method of testing has been much improved since formerly, and the error of a single determination as now carried out probably does not exceed $10^{-12}$ gram of radium. The quantity of radium in the oldest solution is now about $4 \times 10^{-11}$ gram, which is nearly twice as great as initially. During the past year five measurements of the quantity of radium in this solution have been made, and they show that, within the stated limit of error of observation, the production of radium has proceeded during that period proportionally to the square of the time. The tests on the other solution show that in them also the production of radium is now proceeding according to the same law and at a similar rate.

That the initial rate of production of radium from uranium should vary according to the square of the time was deduced mathematically by Rutherford (Jahr. Rad., 1908, v., 164) on the assumption that there was only one intermediate substance of period of life long compared with 